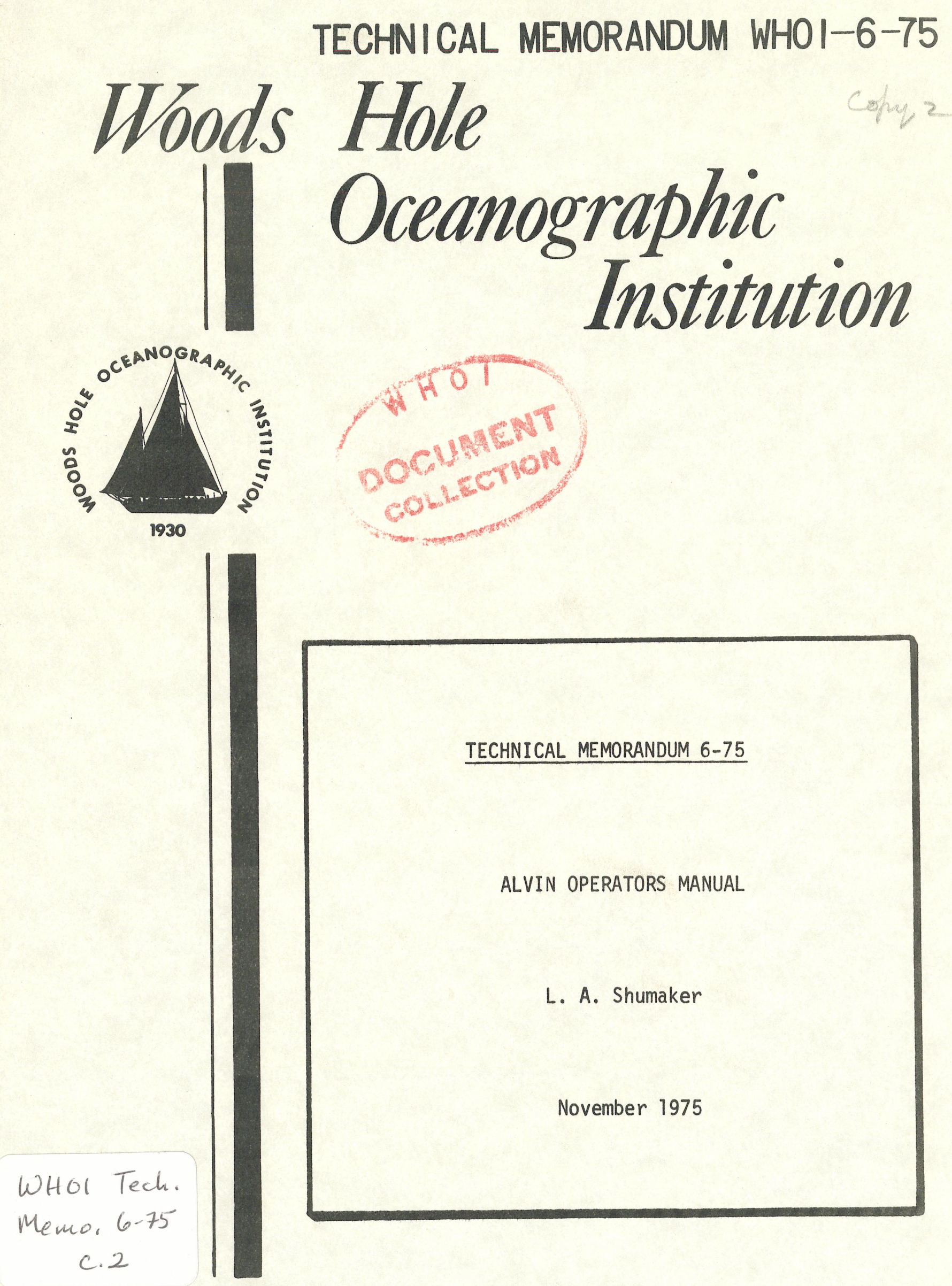

WOODS HOLE, MASSACHUSETTS 02543

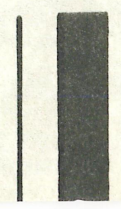


WOODS HOLE OCEANOGRAPHIC INSTITUTION

Woods Hole, Massachusetts

TECHNICAL MEMORANDUM 6-75

ALVIN OPERATORS MANUAL

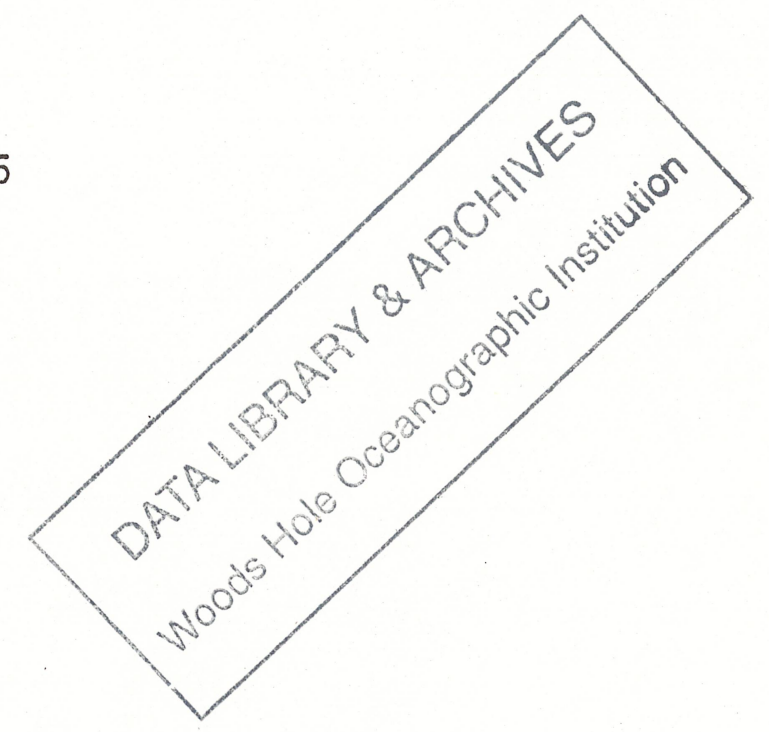

prepared by

L. A. Shumaker

November 1975 
Woods Hole Oceanographic Institution

Woods Hole, Massachusetts

\section{ALVIN Operators Manual}

I. A. Shumaker

November 1975

Approved for Distribution

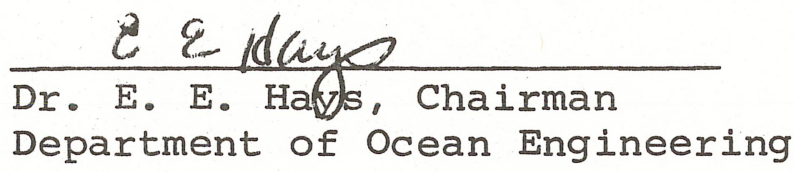


Woods Hole Oceanographic Institution

The ALVIN Operator's Manual has been reviewed and is approved for implementation. This Manual will replace Appendices 4,5 and 6 of Management Plan for the Deep Submergence Research Vehicle Program.

$\frac{\text { C)t 28,1975 }}{\text { Date }}$

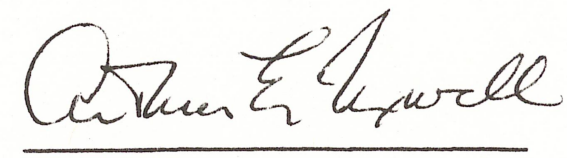

Arthur E. Maswell Provost 
While the format and compilation of these procedures are the work of the author, much of the detailed work is the result of the combined efforts of $J$. D. Donnelly, D. S. Hosom, A. G. Sharp, B. B. Walden and V. P. Wilson, all members of the ALVIN Group. In addition many corrections and additions were made based on review by E. E. Hays, A. E. Maswell, W. O. Rainnie and A. G. Sharp. 


\section{Record of Changes}

I. Purpose

II. Normal Operating Procedures 2

A. General 2

B. Launch and Recovery 2

C. Minimum Requirements for Diving 7

D. Diving 9

E. Surfacing 10

F. Submerged Operations and 11

G. Communications 13

H. Life Support Operation. 18

III. Emergency Operating Procedures 21

A. General 21

B. Fire Procedure 21

C. Emergency Life Support System 22

D. Emergency Battery System 25

E. Atmosphere Control Casualties 28

1. General

2. High $\mathrm{O}_{2}$ Partial Pressure

3. Low $\mathrm{O}_{2}$ Partial Pressure

4. High $\mathrm{CO}_{2}$ Partial Pressure

F. Emergency Surfacing (Jettison) Procedure 31

G. Loss of Contact 36

IV. Vehicle Performance Data 38

A. Ascent-Descent Curves 38

B. Main Ballast Buoyancy Curves 39

C. Main Battery Discharge Curves 40

D. Variable Ballast Curves 41

V. Casualty Procedures and Information for Observer/

Passengers

VI. Pilots Individual Dive Records 47 


\section{Purpose}

The safe operation of the Deep Submergence Research vehicle ALVIN requires a great deal of planning and a high level of competence on the part of all persons concerned with the operation. In particular however it requires that the pilots have a thorough knowledge of the vehicle and the operating procedures which have been developed over a long period of varying types of operations.

The primary purpose of an Operator's Manual is to provide a framework around which pilots may build their knowledge and skills in such a fashion that everyone will know, at least in a general way, how the pilot will react to operational situations and to casualties. This allows the Surface Controller as well as the rest of the support crew to render a maximum of assistance with a minimum of communications and confusion. It must be understood however that under any given circumstance the pilot at that time is the only one who can assess the specific requirements for safe operation and decide on a course of action. In this sense the procedures in this Manual are meant to serve only as guidelines and the pilot is expected to utilize judgement and initiative in the operation of the DSRV.

Sections II and III of this Manual are designed to provide the pilot with uniform procedures to be used for both normal and emergency operations.

In order to further aid the pilot in carrying out these responsibilities, section IV contains specific performance data and other information which may be useful in arriving at a specific course of action.

Section $V$ contains procedures for the observer/passenger to follow in the event that the pilot is incapacitated. These procedures should be explained to the observer/passenger during the predive briefing.

Copies of this Manual, corrected up to date, shall be kept in ALVIN and at the Surface Controller's station at all times. 


\section{Normal Operating Procedures}

A. General The operating procedures covered here provide guidelines for normal operations of the DSRV ALVIN, required to carry out all missions. Specific mission procedures will be promulgated when considered necessary.

While these procedures are to be considered as guidelines, and the pilot is expected to use good judgement and may deviate from them where he considers it necessary, those items designated as Minimum Requirements for Diving in Section II. C., and Operating Limits in Section II. F., are required for Navy Certification or by Institution Policy, and are therefore mandatory. These items will be deviated from only with specific direction from higher authority.

\section{B. Launch and Recovery}

1. General The launch and recovery of the DSRV ALVIN is a joint effort of the Master of the DSRVT (LULU), the Surface Controller and the Pilot in Command of ALVIN. The assignment of personnel to man launch and recovery stations on LULU shall be made by the DSRVT Master from the DSRVT crew and the submarine support crew. When necessary members of the scientific party may also be assigned to assist. Stations for each dive, including Pilot in Command, surface Controller, small boat coxswain and bow hook shall be posted by the Expedition Leader well in advance of the launch. The Crew Chief shall designate from those remaining, the personnel available to the DSRVT Master for assignment to launch and recovery stations.

Specific command and control assignments have evolved from practice and are set forth here for all normal launch and recovery operations. Under unusual circumstances these assignments may be changed, but only with the concurrence of the Master of the DSRVT, the Expedition Leader, the Senior Pilot and the surface Controller. 
a. The Surface Controller has coordination control and is responsible for the conduct of the operation, which includes the DSRV, the DSRVT, plus any additional support units involved.

b. During the actual launch and recovery operations while the DSRV is on the launch cradle or between the hulls of the DSRVT, the Master of the DSRVT is responsible for the evolution as well as the conn of the ship. As the DSRV passes from between the hulls the Surface Controller assumes operational control of the DSRV and the DSRVT.

c. Line handlers and swimmers will receive commands directly from the Pilot in Command (PIC) or the Launch Pilot of the DSRV who also is responsible for maneuvering the DSRV as necessary to execute the launch or recovery. It is imperative that the line handlers pay strict attention to the PIC and no one else.

d. A qualified person shall be assigned to the cradle hoisting controls who is familiar with the system and with possible emergency actions.

\section{Launch}

a. When the submarine and DSRVT pre-dive checklists have been completed and signed by the Crew Chief, Operations Director, Pilot in Command, Surface Controller, DSRVT Master and Chief Scientist the word will be passed to man launching stations. When all stations have been manned and agreement has been reached between the DSRVT Master, Surface Controller and Pilot in Command (PIC) that everything is in readiness the order will be given to stand by to launch the submarine. At this time the submarine will be unmanned with the hatch shut.

b. When ready, the order will be given to lower the submarine. The hoist system operator and the line handlers will take their directions from the PIC. The co-pilot and/or observers 
will stand by on the port hull, prepared to board the submarine.

c. When the cradle is submerged and just prior to the vehicle being waterborne (vehicle draft about 6 feet). The PIC will direct the hoist operator to stop lowering. The PIC will board the submarine and open the hatch. The observer or both observers will board the submarine and go below.

d. Because of the low freeboard of ALVIN, and the possibility of water splashing into the sphere and causing electrical grounds it will be normal procedure at this point for the entire crew of ALVIN including the PIC to enter the sphere and shut the hatch. An off duty pilot will board ALVIN and take over the topside duties of PIC for the launch.

e. When ready the Launch Pilot will direct the hoist operator to continue lowering the cradle until the vehicle is waterborne and the cradle is well clear. (About 10 feet below the vehicle). The Launch Pilot will have complete control of the line handlers during the launch. After maneuvering the DSRV well clear of the DSRVT, the Launch Pilot will return control of the DSRV to the PIC.

f. If in the judgement of the Expedition Leader and the PIC it is safe to do so, the launch may be carried out by the PIC, with the hatch open. This will normally be done only under conditions of very low sea state.

\section{Recovery}

a. When the submarine has arrived on the surface, the DSRVT Master will pass the word to stand by to recover the submarine.

b. When all stations have been manned and the DSRVT is on the proper heading (normally down wind) the hoist operator will be directed to lower the cradle. 
c. The small boat may carry an off-duty pilot to the DSRV where he will assume topside control for the recovery. If in the judgement of the Expedition Leader, and the Surface Controller it is safe to do so however, the PIC may open the hatch and come topside to carry out the recovery himself. This will be done only under low sea state conditions.

d. When everything is in readiness the Recovery Pilot will commence his approach. The line handlers and the hoist operator will take commands directly from the Recovery Pilot during the actual recovery.

e. When the vehicle has been positioned over the cradle the Recovery Pilot will direct the hoist operator to raise the cradle. After the vehicle has landed on the cradle and the vehicle draft is about six feet the Recovery Pilot will direct the hoist operator to stop the hoist. The observers, Co-pilot, PIC and Recovery Pilot will disembark. The hatch will be shut. The PIC will direct the hoist operator to hoist away and the cradle will be stowed on its chocks. The submersible shall be gripped down as soon as possible after the cradle reaches the stowed position.

4. Recovery in Rough Seas Although ALVIN will not be launched for a dive if rough weather is eminent, weather and sea conditions are not predictable enough to preclude a recovery being necessary in rough weather. In the event that a rough weather recovery becomes necessary the following steps will be taken in addition to normal recovery procedures:

a. At the first indication of a rough weather recovery the pilot should be notified in order that he may conserve his battery. If the surface controller deems it necessary he may order the pilot to surface as soon as possible. 
b. Handling lines will be lengthened to allow attachment to the submarine at a greater distance.

C. Extra swimmers will be suited up and stationed on the catamaran hulls to act as life guards.

d. All unassigned personnel will be stationed to assist the line handlers.

e. Life jackets will be issued to and worn by all hands.

f. Upon surfacing the pilot will remain in the submarine with the hatch shut unless otherwise directed by the surface controller.

9. A qualified pilot will board the submarine to operate it during the recovery. (If two qualified pilots are in the submarine and in the Surface Controller's judgement it is safe to do so, the hatch may be opened and one on board pilot go topside to operate the boat. The hatch should be shut as soon as communications are established between the two pilots)

h. All disposable weights will be dropped and the variable ballast system emptied if sufficient battery power remains to do so without lowering propulsion power.

i. Samples and tools will be removed from the sample tray and placed in the small boat if it is safe for the swimmers to do so.

j. Swimmers will attach handling lines to ALVIN while still well astern of the catamaran and then return to the small boat.

k. If an escort vessel is present it will be stationed well astern of the catamaran in a position to pick up any personnel who may be lost overboard.

1. When all of the above steps have been taken, the recovery will proceed in normal fashion. 


\section{Minimum Reguirements for Diving}

Under normal circumstances it is expected that all equipment on ALVIN and LULU will be operational. There are however many equipments on both vessels which have no impact on the operational safety of ALVIN. It is left to the discretion of the Expedition Leader and the Pilot-in-Command which and how many of these equipments may be out of commission and still allow ALVIN to make a useful dive.

Those equipments and systems listed below however, are considered vital to the operational safety of ALVIN and must be operational at any time that ALVIN submerges. In some cases loss of the equipment during the dive will not constitute a reason for aborting the dive if adequate backup is available. Such cases are specifically called out below.

1. All normal and emergency life support equipment shall be operational and fully charged with the following exceptions:

a. Oxygen bottles may be below full charge, in the case of repetitive dives only, as described in the section of this Manual on Life Support Operation.

b. The automatic $\mathrm{O}_{2}$ and $\mathrm{CO}_{2}$ sensors may be out of commission if adequate backup equipment is aboard.

2. All communications equipment including radio, underwater telephone and walkie-talkie shall be operational. If underwater telephone communications are lost during a dive, the dive may be continued in accordance with section II-G of this Manual.

3. All service weight droppers shall be operational with the exception that the forward and aft droppers may be out of commission if no equipment is carried on them.

4. The jettison systems for the main batteries and the afterbody shall be operational. 
5. At least one light, illuminating the pilots viewing area, shall be operational.

6. At least two independent depth readout systems shall be operational.

7. One fathometer shall be operational unless the dive is planned for mid-water operations only.

8. Three emergency batteries shall be on board and fully charged.

9. The main propulsion system shall be operational.

10. One tracking system shall be fully operational.

11. The Leak Detector shall be operational.

12. The Ground Detector shall be operational.

13. The Radio Beacon shall be installed and energized.

14. The Identification Light shall be installed and energized.

15. The Emergency Transponder shall be operational.

16. The following equipment shall be on board:
a. Hull Release T-bar Wrench
b. Life Jackets (3)
c. First Aid Kit
d. Radar Reflector
e. Emergency Rations and Water
f. Flare Kit
g. Fire Extinguisher
h. Walkie-Talkie 
i. Two Sound Powered Hand Sets

j. Three "Space" Blankets

k. Manual Atmosphere Monitoring Kit with 12

$\mathrm{O}_{2}$ and $12 \mathrm{CO}_{2}$ tubes. (If automatic monitors are out of commission, 24 of each type should be on board.)

1. ALVIN Operator's Manual

\section{Diving}

The submarine will normally be submerged in the following manner after the necessary checks of its satisfactory condition for diving have been made:

1. Report check list complete and request permission to dive.

2. Upon receipt of permission to dive open main ballast vents and flood main ballast tanks completely.

3. Adjust trim and buoyancy as necessary.

4. Use lift props, when they are submerged, as necessary to aid in submerging (be aware of swimmers near surface).

5. Upon completely submerging, shut main vents for emergency $M B$ blow if required.

6. At 20 to 40 meters keel depth cycle main vents to exhaust any trapped air and check all systems for normal operation. Shut main vents upon completion.

7. During descent the following items should be monitored for normal operation periodically:
a. V.B. System
b. M.B. System
C. HP Air Bank Pressure
d. Cabin Pressure 
e. Grounds

f. Battery Voltage

g. Lights

h. Fathometer

i. Depth Indicators

j. Leak Detectors

k. $\mathrm{O}_{2}$ Pressure

1. $\mathrm{O}_{2}$ and $\mathrm{CO}_{2}$ Partial Pressures

8. Drop descent weight(s) at about 50 to 60 meters above bottom and adjust variable ballast and trim angle as bottom is approached or desired depth is reached.

9. Position lift props to cushion contact with bottom if part of dive.

10. Obtain "neutral trim" and report to Surface controller as soon after reaching bottom, or assigned depth, as practical.

\section{E. Surfacing}

The submarine will normally be surfaced in the following manner:

1. After obtaining permission from Surface Controller to come up, drop ascent weight if carried, and adjust variable ballast to as light a condition as appropriate for the depth of water. Use power, if necessary, to drive to surface.

2. Continue rise to between $40 \mathrm{~m}$ and $20 \mathrm{~m}$ keel depth adjusting to neutral buoyancy. Cycle vents and leave shut. NOTE: On deeper dives where larger amounts of weight are dropped to return to the surface it may not be possible 
to stop near the surface. When this is the case the Surface Controller must be particularly alert to insure that the area is clear and to order the PIC to stop his ascent while still deep, if any surface interference is anticipated.

3. Level off at 20 meters keel depth unless otherwise instructed by the surface controller. Search $360^{\circ}$ acoustically and visually for interference from surface units. Approach surface cautiously. Notify Surface Controller of depth and request permission to surface.

4. Check vents shut, ascend to near surface and blow main ballast tanks. Remain alert to vent tanks if necessary. Continue blowing until normal surface draft is achieved.

5. Turn on and test radiotelephone. If not working, do same with walkie-talkie, using jumper lead to connect antenna.

6. Obtain permission from Surface Controller to open hatch.

7. After surfacing, prepare for recovery as directed by Surface Controller. The Recovery Pilot of the DSRV must be aware of the presence of swimmers to avoid injury by propellers to them, and be prepared to assist in the recovery procedure by judicious use of vehicle propulsion, not only to prevent collision with the support ship, but also to prevent injury to swimmers between the submarine and the support ship. The Recovery Pilot shall direct the line handlers and assist their efforts with the DSRV propulsion as appropriate.

\section{F. Submerged Operations and Operating Limits}

During normal submerged operations the various combinations of conditions of visibility, terrain roughness, currents, etc. are infinitely variable and no set of operating instructions could hope to 
cover the responses required to accomplish any particular mission under all conditions. The pilot must rely on his own experience and that of other pilots coupled with a thorough knowledge of what the submersible is capable of doing. It has been possible however to establish an envelope of general environmental and ship status limits within which ALVIN may be operated without undue risk to either personnel or equipment. These limits, listed below, are not to be exceeded except in the case of a preplanned mission which specifically addresses the limit to be exceeded and is approved by the proper authority, or when in the judgement of the Pilot-in-Command it is necessary to insure the safety of personnel.

1. ALVIN shall not be operated in an area where the water depth exceeds 4026 meters without the express written consent of the Director of the Woods Hole Oceanographic Institution.

2. ALVIN shall not be operated below a depth of 3660 meters.

3. ALVIN shall not be operated in such a fashion as to pass under any object either natural or man-made.

4. ALVIN shall remain clear of wreckage, debris or natural terrain features which have entanglement or entrapment potential.

5. ALVIN shall remain clear of any explosive devices which may be sighted.

6. Excessive currents or low visibility may be cause to terminate a dive or a phase of an operation when in the judgement of the Pilotin-Command the mission cannot be safely carried out.

7. Loss of all communications for 30 minutes beyond normal call up time shall be cause for termination of a dive. Specific procedures are covered in section II-G. 
8. Ground detector readings below 30,000

ohms on the 30 volt buss or $60,000 \mathrm{ohms}$ on

the 60 volt buss shall be cause for term-

inating a dive if they cannot be cleared from the buss within a reasonable time.

9. Leak detector indication below 10,000 ohms shall be cause for terminating a dive. Particular care must be taken to initiate surfacing procedure immediately if the leak indication appears in the electrical disconnects as loss of all normal vehicle controls could result.

10. On any dive below 3000 meters the variable ballast system shall contain a pre-charge pressure of $850 \mathrm{psi}$. In the event of improper functioning of the variable ballast pressure readout a dive shall not exceed 3000 meters.

11. On any dive below 3000 meters the high pressure main ballast air tanks must have a minimum pressure of 850 psi while below 3000 meters. In the event of improper functioning of the high pressure air readout a dive shall not exceed 3000 meters.

12. The Pilot-in-Command shall terminate a dive by whatever means necessary at any time that he feels a hazard to the submersible or personnel exists, without regard to mission success or completion.

\section{G. Communications}

This procedure covers the normal operation of the ALVIN communications equipment including the underwater telephone and the VHF radio, as well as the back up procedures to be used in the event of a malfunction in either piece of equipment.

1. Underwater Telephone (UQC)

Prior to diving, communications should be 
established with the Surface Controller on the UQC. When this is not possible due to poor near surface sound conditions, a dive may still be initiated, using the radio, at the Surface Controller's discretion. In any case, the radio should remain on until the submarine is completely submerged. During descent and ascent, depth and status should be reported periodically. As a general rule, the following items should be reported during the dive:

By the submarine:

a. Significant depth changes.

b. Significant course changes when cruising.

C. Significant changes in activity such as from cruising to all stop to take samples.

d. Arrival at specific objectives.

e. Explosives sighted.

f. Large artifacts sighted.

9. Release of descent and ascent weightsinclude number of weights dropped and depth of submarine.

h. Casualties to personnel or the submarine.

By the surface controller:

i. Significant changes in weather.

j. Casualties to the support ship or to equipment which may affect the operation.

The Surface Controller shall keep an accurate record of all UQC communications in the surface controller's log. The record should include time, adequate text to insure that the full meaning of the message is reflected and an indication of the originator of the message, i.e., submarine or surface. 
When for any reason no communication is initiated for 30 minutes, the Surface Controller shall be responsible for initiating a call up to insure that the equipment is functioning properly. If communications cannot be established by voice, then the CW mode should be used, utilizing the brevity code set forth in Table II-G-I.

If the submarine UQC is inoperative, the Pilot should transmit at $5 \mathrm{KHz}$ using the code pushbutton on the blue clock box, and listen on the backup receiver. Since the Surface Controller has two complete UQC's, no specific backup is provided at this station, however when the submarine utilizes the $5 \mathrm{KHz}$ code transmitter the Surface Controller must shift the marker receiver to $5 \mathrm{KHz}$ to receive. He should transmit using the CW key on his UQC.

At any time that communications cannot be established within 60 minutes of the last successful communication the dive should be aborted and the submarine surfaced. Attempts to establish communications should be continued until the submarine is surfaced and communications established on the radio or visually.

2. VHF Radio

The VHF radio installed on ALVIN and LULU at the surface controllers station, has six channels. Channel usage shall be in accordance with the table below.

\begin{tabular}{|c|c|c|}
\hline Channel & Freg. $(\mathrm{MHz})$ & Use \\
\hline 6 & 156.30 & Intership Safety \\
\hline 13 & 156.65 & Navigation \\
\hline 16 & 156.80 & Distress and Call Up Only \\
\hline $19 A$ & 156.95 & Intership - All WHOI Ships Have \\
\hline 70 & 156.525 & Intership - Routine \\
\hline 72 & 156.625 & Intership - Routine \\
\hline
\end{tabular}


Table II-G-1

Underwater Brevity Code

Meaning

\begin{tabular}{|c|c|c|}
\hline CW Signal & Transmitted by sub & Transmitted by Surf \\
\hline$A A$ & Call & Call \\
\hline $\begin{array}{l}\mathrm{BB} \\
-\cdots-\cdots\end{array}$ & On bottom, operating normally & Are you on bottom? \\
\hline $\mathrm{DD}($ Numerals) & My depth is ___(hundreds of meters) & $\begin{array}{l}\text { Sent without numerals } \\
\text { What is your depth? }\end{array}$ \\
\hline SS & I am surfacing & Surface \\
\hline $\begin{array}{l}\text { II } S S \\
\ldots \ldots \ldots\end{array}$ & Request permission to surface & Are you surfacing? \\
\hline RR SS & -- & All clear to surface \\
\hline $\begin{array}{l}\text { NNN } \\
-\bullet-\cdot-\cdot\end{array}$ & Unable to surface & Do not surface \\
\hline RR & Rodger & Rodger \\
\hline $\begin{array}{l}\text { GG } \\
-\cdots \ldots\end{array}$ & I am descending & Are you descending? \\
\hline VV $\cdots-\cdots-$ & Request Vector & $\begin{array}{l}\text { Vector }-\frac{1}{\text { numerals representing }} \\
\text { true bearing in } 10^{\circ} \mathrm{s} \\
\text { of degrees }\end{array}$ \\
\hline$x x$ & I am emergency surfacing & Surface Immediately \\
\hline $\mathrm{XX} 1$ & Have released all weights & Release Weights \\
\hline $\mathrm{xx} 3$ & Have released battery & Release Batteries \\
\hline$x \times 5$ & Have released sphere & Release Sphere \\
\hline
\end{tabular}

All messages sent with brevity code should be sent twice, with each character sent slowly and distinctly and at least 3 seconds between groups. Messages not covered, should be spelled out. 
All transmissions will be in accordance with FCC rules and procedures. During a dive, while ALVIN is submerged, the Surface Controller should monitor Channel 16. If an emergency surfacing is necessary, or upon ALVIN surfacing after loss of UQC communications, initial call up should be on Channel 16 .

All communications will be logged in the Surface Controllers log, with an indication to show that they are VHF radio communications. Actual radio logs for ALVIN and LULU VHF transceiver will be updated when required, from the Surface Controllers log. 


\section{H. Life Support Operation}

\section{Oxygen Supply}

Three oxygen storage flasks of ICC designation GE730 are provided in the personnel sphere. Each is equipped with a close coupled oxygen regulator which reduces the oxygen pressure to 50 PSIG. During normal operation, the shut off valve of one oxygen flask should be opened and the mode selection valve should be set in the normal position. In this condition, oxygen will flow from the flask to the adjustable delivery flow meter and out into the personnel sphere atmosphere. The expected level of personnel activity in the submarine is such that an oxygen consumption rate of approximately .5 standard liters per minute ( 1 standard cubic foot per hour) per man can be expected. Therefore, the flow meter needle valve should be adjusted to provide an oxygen flow rate of approximately 1.5 liters per minute at the start of a three man dive. Oxygen concentration readings should be checked at least twice an hour and the flow rate adjusted to maintain an $\mathrm{O}_{2}$ partial pressure between .18 and .23 atmospheres ( $18 \%$ to $23 \%$ oxygen for 14.7 PSIA personnel sphere pressure). See Sections III-E-1 and III-E-2.

At the start of a dive, each of the three oxygen flasks should be charged to between 2250 PSIG and 2475 PSIG. This results in a total oxygen quantity of between 208 and 230 standard cubic feet yielding a three man life support capability of approximately 72 hours.

\section{Carbon Dioxide Removal}

The air regeneration unit in the personnel sphere consists of a blower, a dust filter, an 8 oz. activated charcoal filter and lithium hydroxide canisters containing 6.4 pounds of LiOH. LiOH can be expected to absorb .8 pounds of $\mathrm{CO}_{2}$ per pound. This indicates that with an assumed respiratory quo- 
tient of .85 , one $\mathrm{LiOH}$ canister will last 17.8 hours for a three man dive (53.4 manhours). Three spare $\mathrm{LiOH}$ canisters are carried in the personnel sphere which increases the $\mathrm{CO}_{2}$ absorption capability to 71.2 hours for a three man dive (213.6 manhours). In addition, the emergency life support system has a $\mathrm{CO}_{2}$ absorption capability of approximately 18 man hours.

The $\mathrm{CO}_{2}$ level in the personnel sphere should be monitored at least twice an hour. Corrective steps must be taken whenever the partial pressure of $\mathrm{CO}_{2}$ exceeds .015 atmospheres $\left(1.5 \% \mathrm{CO}_{2}\right.$ at 14.7 PSIG personnel sphere pressure). See section III-E-3. It should be noted that the effect of $\mathrm{CO}_{2}$ is time related; for example a $\mathrm{CO}_{2}$ partial pressure of .02 atmos ( $2 \%$ at 14.7 psig) will produce minor perceptive changes after 10 minutes and distractive discomfort after approximately 2 hours.

\section{Normal Gas Concentrations}

Under normal conditions levels of $\mathrm{O}_{2}$ and $\mathrm{CO}_{2}$ shall be maintained within the following limits:

\begin{tabular}{|c|c|c|c|c|}
\hline & Normal & Maximum & & imum \\
\hline & \% & $\underline{\mathrm{mm} \mathrm{Ha}}$ & $\%$ & $\mathrm{~mm} \mathrm{Hg}$ \\
\hline $\mathrm{O}_{2}$ & 23 & 175 & 18 & 137 \\
\hline $\mathrm{CO}_{2}$ & 1.5 & 11.4 & - & - \\
\hline
\end{tabular}

When these limits are exceeded the appropriate procedures in section III shall be initiated.

4. Waiver of $\mathrm{O}_{2}$ Quantity Requirement

When conducting repetitive dives without recharging the main batteries, the requirement for three fully charged $\mathrm{O}_{2}$ bottles may be waived to the extent that the on service bottle pressure may be reduced to the value calculated by the following formula: 


$$
\mathrm{p}_{1}=187.5\left(12-\mathrm{t}_{\mathrm{e}}\right),
$$

where $p_{1}$ equals minimum bottle pressure allowed and $t_{e}$ equals total time in hours submerged since the last battery charge.

All other reguirements remain the same.

5. Monitoring Equipment

$\mathrm{O}_{2}$ and $\mathrm{CO}_{2}$ percentages are normally monitored through the use of an Atmospheric Oxygen Monitor, and an Atmospheric $\mathrm{CO}_{2}$ Monitor. In addition a manually operated gas analyzer with both $\mathrm{O}_{2}$ and $\mathrm{CO}_{2}$ detector tubes is provided for backup. The installed monitors are battery powered and independent of ship's power. 


\section{Emergency Operating Procedures}

A. General While no set of procedures could hope to cover all possible emergency situations which might occur during the operation of a deep submersible and the safety of the submersible will always be dependent upon the skill and knowledge of the pilot, a set of procedures covering the obvious possibilities serves as a nucleus for a pilot to build upon. With these procedures as a basis and utilizing his own knowledge of the submarine, the pilot should be able to handle any contingency.

Once the decision has been made to initiate an emergency procedure the procedure should be followed as closely as is possible, thereby insuring that the surface controller will know what is taking place with a minimum of communications. Any deviations from a specific procedure should be reported to the surface controller as soon as possible. When any unusual mission or operation is planned which might involve hazards not covered here or which would require deviation from normal operating procedures, specific emergency procedures will be promulgated to cover the situation and appended to this manual for the duration of that operation.

\section{B. Fire Procedure}

1. General In the event of fire or suspected fire of any type on board ALVIN during any period when the hatch is shut, the procedures listed below will be followed unless, in the judgement of the pilot-in-command, deviation is required in the interest of safety. Normally, in the event of a fire, the mission will be terminated and the submarine will be surfaced as soon as practicable consistent with the conditions existing in the submarine and on the surface.

2. Pre-Dive Prior to the start of actual diving operations, observers and/or passengers will be given a thorough briefing in the use of emergency 
breathing equipment, including actual wearing of, and breathing with, the complete system.

3. Specific Procedures

\section{Pilot}

Shift oxygen supply to the emergency system and order all personnel to don emergency breathing equipment.

Secure all power to affected area as necessary and practical depending on the operational situation and the nature of the fire.

Use installed chemical fire extinguisher as required. Check passenger's breathing equipment for tightness and proper functioning.

Inform surface control of casualty and status. Initiate surfacing procedures in line with conditions in the boat.

\section{Passenger/Observers}

Don emergency breathing gear when ordered. Remain quiet, breathing normally, and move only as directed by the pilot.

\section{Emergency Life Support System}

1. General The emergency life support system consists of three oxygen rebreathers type DS, manufactured by MSA Research Corp. They are intended to provide protection in the event of the occurrence of a toxic or noxious atmosphere as well as an oxygen deficient atmosphere. They do not extend the life support duration capability of the submarine beyond the 72 man hour limit of the normal life support system.

Oxygen is supplied to the rebreathers from the life support oxygen bottles at a pressure of 50 psig. Each rebreather consists of a closed 
breathing bag to insure an adequate gas volume within the system, a full face mask with oral-nasal cup and a $\mathrm{CO}_{2}$ absorption canister. In addition, a mask purge and face plate defogger is included and the pilot's unit contains a microphone allowing use of the underwater telephone. A typical rebreather is shown in Figure III-C-I.

The $\mathrm{CO}_{2}$ absorption canisters are constructed of clear acrylic plastic and are charged with approximately 2 pounds of 4-6 mesh indicating Baralyme. Tests have shown that each of these canisters is adequate for 6 hours duration under minimal activity conditions but every attempt should be made to limit their use to 3 hours.

2. Operational Procedure The emergency rebreathers should be used whenever there is an actual or suspected problem with the personnel sphere's atmosphere. All three rebreathers are activated by turning the life support mode selection valve from the normal to the emergency position which diverts the oxygen flow from the normal life support flow meter to the rebreathers. Oxygen supply pressure to the rebreathers can be read on the discharge side of the regulator associated with the supply bottle in service and should be 50 psig.

The following is a step by step procedure for utilizing the rebreathers and insuring their proper operation:

1. Detach the mask from its hanger and orient it in the proper position for wearing without kinks or twists in the breathing hoses.

2. Remove the rubber stopper seal from the oral-nasal cup in the mask.

3. Grasp the sides of the mask between the thumbs and forefingers and insert the chin into the mask as far as possible. Slip the fingers back along the two pairs of side 


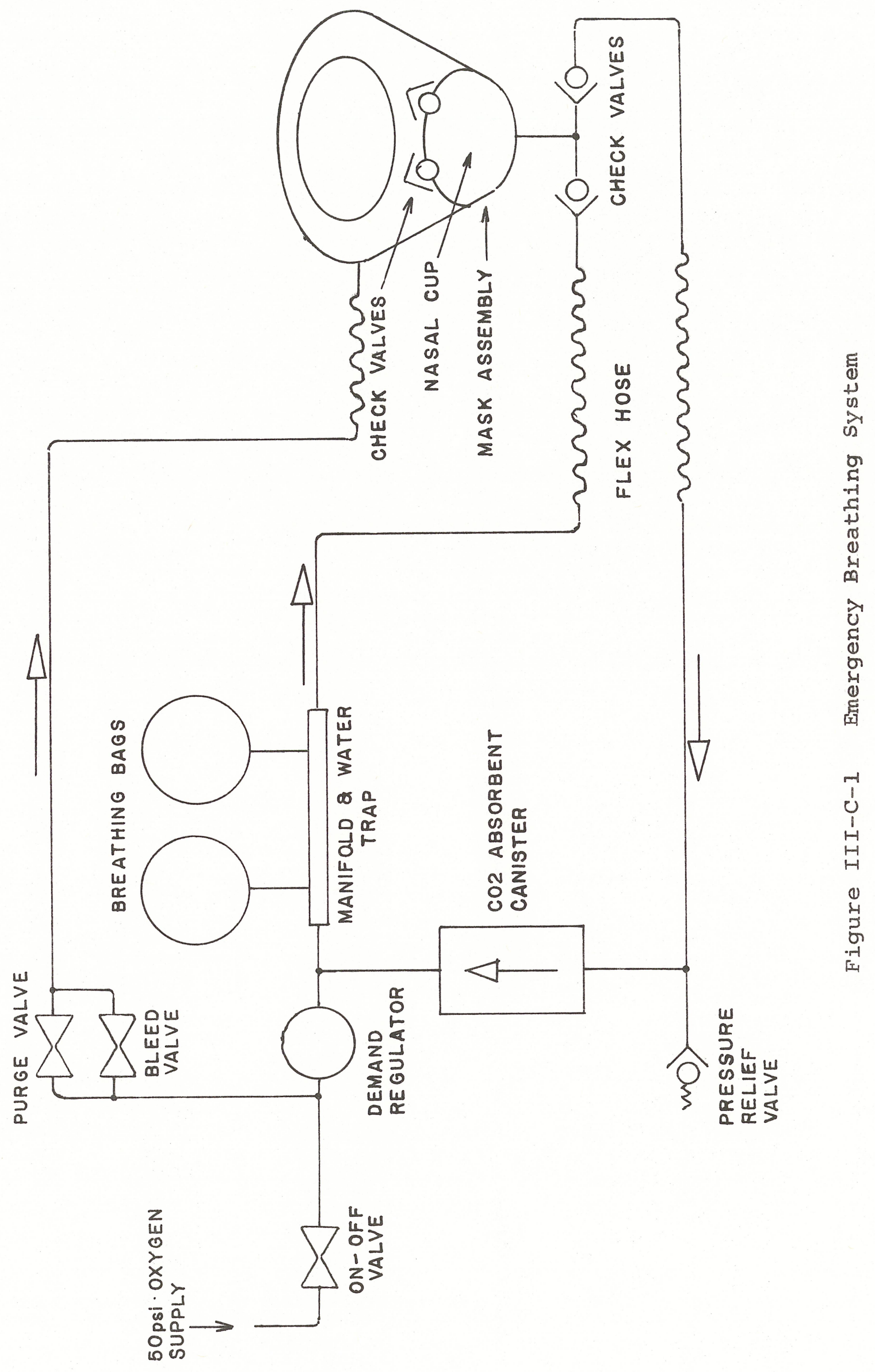


head straps, pulling the straps up and back over the top of the head. Check the straps to insure that they are not twisted.

4. Tighten the mask in place by pulling the strap adjustment tabs starting with the lower side straps and ending with the upper central strap.

5. Purge the mask if necessary using the black handled toggle valve located on the rebreather mounting tray. This valve is spring loaded and will return to the off position when released. A purge time of approximately 5 sec. should be sufficient.

If breathing is difficult and/or the purge valve has no noticeable effect check to insure that the mode selection valve is in the emergency position and that the on-off valve associated with each rebreather is in the on position. The latter valves have green handles and are located on the rebreather mounting trays. They are normally in the on position. Difficult breathing may also be caused by fouled breathing bags. These must be free to inflate without hindrance and should be checked for proper operation if problems are suspected.

6. Check the mask for leaks by turning off the on-off valve associated with the rebreather in question and inhale so that the face piece collapses slightly. The face piece should remain collapsed as long as the breath is held. If any leakage is noticed around the mask, readjust the head straps. Return the on-off valve to the "on" position for normal operation.

3. Casualties During use, the demand regulator on each rebreather should admit oxygen into the system audibly every two or three breaths. If a regulator fails shut, breathing will become difficult and the mask will tighten against the 
wearer's face with every inhalation. This situation can be overcome by using the micrometer needle valve located on the rebreather mounting plate. This valve admits an adjustable continuous flow of oxygen into the mask face plate area from which it can be drawn into the oral-nasal cup by check valves provided. Flow should be adjusted until easy breathing is obtained without excessive outward leakage around the mask. A micrometer setting of approximately 125 should be adequate.

If a demand regulator should fail open, a continuous flow of oxygen will be heard entering the breathing circuit and exhausting from the circuit relief valve. In this event, the only recourse is to use the rebreather's on-off valve to control the flow either by providing oxygen only when breathing resistance increases or by adjusting it to provide limited continuous flow.

\section{Emergency Battery System}

1. General The emergency battery consists of three 30 volt packs of Nickel-Cadmium cells. Each of the three packs has a rated capacity of 4 amperehours, giving a total rated capacity of 12 amperehours. The normal charging, maintenance and service of the battery packs is designed to ensure more than $90 \%$ of rated capacity. To account for the remote possibility that one or more of the battery packs might not be up to greater than $90 \%$ rated capacity the power budget is conservatively based on 9 ampere-hours (75\% of rated capacity).

Each battery pack must be fully charged prior to a dive and must show a minimum of 31 volts under an eight ohm load during the predive checks.

There are two circuits which can be powered with the emergency battery. The GREEN bus applies power to the Service Bus through the NORMAL/EMERG selector switch. Equipments receiving power from the Service Bus are:

a. Gyrocompass

b. Service weight droppers solenoids (4) 
Figure III-D-I

Emergency Power system
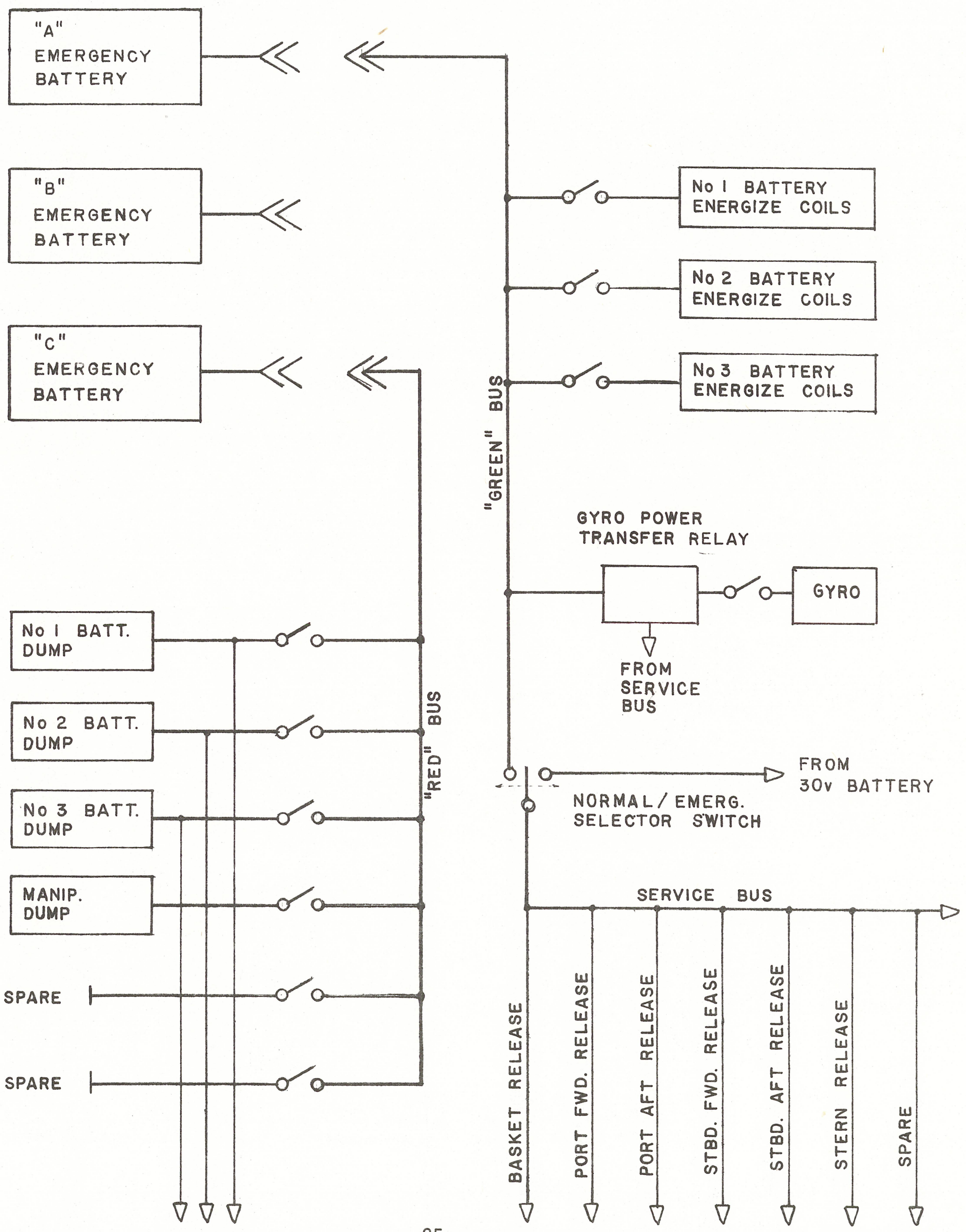
c. Basket drop solenoid

d. Spare drop circuits (2)

e. Main ballast blow solenoids

f. Main ballast vent solenoids

g. $\mathrm{CO}_{2}$ blower

$\mathrm{h}$ 。 Underwater telephone

i. Tracking and navigation system (thru fuses)

j. $37 \mathrm{KHz}$ pinger disable relay

k. Emergency transponder disable relay

1. 12 volt power supply for the radio and manipulator

m. Tracking pinger cut-off relay

In addition the GREEN bus supplies power directly to the main battery energizing switches and to the gyrocompass power transfer relay.

The RED bus applies power to the emergency dump circuits which include:

$$
\begin{aligned}
& \text { n. Main battery dump solenoids } \\
& \text { o. Manipulator dump solenoids } \\
& \text { p. Spare dump circuits (2) }
\end{aligned}
$$

Each bus terminates in an appropriately colored Amphenol connector which can be mated to any one of the three emergency battery packs. Figure III-D-1 is a single line diagram of the Emergency Power System.

2. Operating Procedures One battery pack is connected to the GREEN bus during the predive checks in order to energize the main batteries. The service bus NORMAL/EMERGENCY selector should be in the NORMAL position and the gyro power switch on the starboard distribution panel OFF before connecting a battery to the GREEN bus in an emergency. The RED bus should be connected to a battery pack ONLY when actual jettison of the batteries and/or manipulator is anticipated, and the precautions for emergency surfacing outlined in section III-F have been carried out.

When for any reason, normal 30 volt power to the sphere is lost, the emergency battery may 
TABLE III-D- I

Emergency Power Budget

\begin{tabular}{|c|c|c|c|}
\hline Equipment & $\begin{array}{l}\text { Current } \\
\text { Used }\end{array}$ & $\begin{array}{c}\text { Duration } \\
\text { of Use }\end{array}$ & Total \\
\hline $\begin{array}{l}\text { Underwater Phone } \\
(U Q C) \text { - Listen }\end{array}$ & 1.0 amps & 2 hrs. & 2.0 amps-hrs. \\
\hline Transmit & 16.7 amps & $\begin{array}{l}3 \min 20 \text { sec. } \\
(10-20 \text { sec. } \\
\text { periods })\end{array}$ & .93 amp-hrs. \\
\hline Radio - Listen & .5 amps & 2 hrs. & 1.00 amp-hrs. \\
\hline Transmit & 4.0 amps & $\begin{array}{l}3 \min 20 \text { sec. } \\
(10-20 \text { sec. } \\
\text { periods })\end{array}$ & .22 amp-hrs. \\
\hline $\mathrm{CO}_{2}$ Blower & 1.6 amps & 2 hrs. & 3.20 amp-hrs. \\
\hline Main Ballast Blow & 1. 25 amps & $2.4 \mathrm{~min}$. & .10 amp-hrs. \\
\hline Main Ballast Vents & 4.3 amps & $5.0 \mathrm{~min}$ & .36 amp-hrs. \\
\hline Weight droppers (5) & $\begin{array}{c}6.0 \text { amps } \\
\text { ea. }\end{array}$ & 2 sec. ea. & .25 amp-hrs. \\
\hline $\begin{array}{c}\text { Energize Main } \\
\text { Batts }\end{array}$ & 6.0 amps & $\begin{array}{l}5 \text { tries } \\
3 \text { sec. ea. } \\
\text { Total }\end{array}$ & $\frac{.075 \text { amp-hrs. }}{8.135 \text { amp-hrs. }}$ \\
\hline
\end{tabular}


be used to power essential equipments on the Service Bus by shifting the NORMAL/EMERG switch to the EMERG position. Prior to shifting to EMERG the following equipments should be secured.

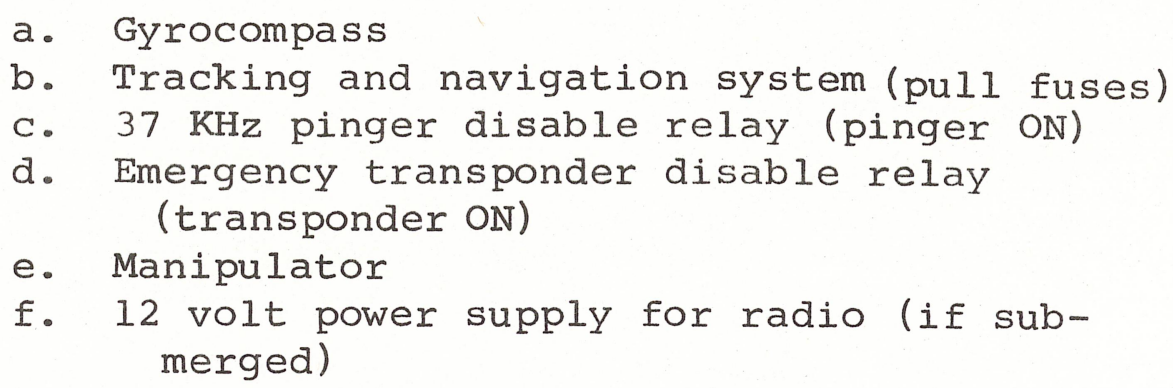
merged)

3. Limitations Because of the limited capacity of the emergency batteries great care must be taken to restrict power expenditure under emergency conditions. Table III-D-1 shows a power budget for two hours of usage. This is based on the assumption that anytime that normal 30 volt power is not available, the pilot will initiate surfacing procedures and that two hours is adequate time to reach the surface from 12,000 feet.

Table III-D-I should be used only as a guideline since each situation will differ. Usage of the $\mathrm{CO}_{2}$ blower can be decreased significantly by setting up a schedule, i.e. 5 minutes on, 10 minutes off, and carefully monitoring the $\mathrm{CO}_{2}$ level. In any case the pilot should keep a careful log of equipment usage in order to maintain a continuous estimate of remaining ampere-hours and insure that he does not expend the power available before accomplishing all necessary tasks.

\section{E. Atmosphere Control Casualties}

1. General Maintenance of the breathing atmosphere within the narrow limits required by human beings is one of the most critical duties of the pilot. Even slight changes in the normal percentages of atmospheric gases can 
have adverse effects on personnel capabilities. It is therefore of utmost importance that the pilot be familiar with all aspects of the life support system, the causes and effects of atmosphere imbalance and the procedures necessary to correct for it. The procedures presented here provide a basis for actions to be taken in the event of malfunction of the life support system.

2. High $\mathrm{O}_{2}$ Partial Pressure In the event of an indication of high $\mathrm{O}_{2}$ partial pressure, above $175 \mathrm{~mm} \mathrm{Hg},(23 \%)$ the bottle stop valve on the oxygen bottle in service should be shut. Reserve bottle valves should also be checked for tight closure. When the $\mathrm{O}_{2}$ level drops to 160 $\mathrm{mm} \mathrm{Hg}$ the service bottle should be put back on the line and the flowmeter adjusted to maintain $160 \mathrm{~mm} \mathrm{Hg}$. If the $\mathrm{O}_{2}$ level continues to rise despite reasonable flowmeter adjustments, the entire system should be checked for leaks, the Beckman Minos AOM should be compared with Drager readings and the $\mathrm{O}_{2}$ supply should be shifted to another $\mathrm{O}_{2}$ bottle in case of a failed regulator.

If the $\mathrm{O}_{2}$ partial pressure exceeds $190 \mathrm{~mm} \mathrm{Hg}$ (25\%), surfacing procedures should be initiated immediately, and all non-vital electrical equipment should be shut down with only absolutely necessary operations continued. In addition, the fire extinguisher should be taken out of its mounting and made ready for immediate use. Personnel should be prepared to utilize the emergency breathing equipment.

Excessive amounts of $\mathrm{O}_{2}$ in the sphere will raise the total cabin pressure as well as the partial pressure of $\mathrm{O}_{2}$ resulting in a fire hazard as well as the possibility of oxygen toxicity problems. One full bottle of $\mathrm{O}_{2}$ emptied into the sphere will raise the total pressure to approximately 1.6 atmospheres and the partial pressure of oxygen to .8 atmospheres. With 
this combination the average person at rest will not show oxygen toxicity symptoms in less than 5 or 6 hours. However, if a second bottle is emptied into the sphere the total pressure will reach 2.2 atmospheres and the partial pressure of $\mathrm{O}_{2}$ will reach 1.4 atmospheres. Under these conditions oxygen toxicity symptoms may be observed within 45 minutes. For this reason it is extremely important that no more than one bottle be on service at any given time and that any significant rise in $\mathrm{O}_{2}$ partial pressure be dealt with immediately.

3. Low $\mathrm{O}_{2}$ Partial Pressure Low oxygen partial pressure is usually caused by an improperly set flowmeter and can easily be corrected by increasing the $\mathrm{O}_{2}$ flow rate. When this fails to correct the problem and the $\mathrm{O}_{2}$ bottle on service has adequate pressure, the $\mathrm{O}_{2}$ Monitor should be checked using the Drager atmosphere analyzer. The dive may be continued using the Drager if the $\mathrm{O}_{2}$ Monitor has failed and all other indications show that the atmosphere control system is functioning properly. If the $\mathrm{O}_{2}$ Monitor readings are correct, the service regulator may have failed and the $\mathrm{O}_{2}$ supply should be shifted to another bottle.

In the unlikely event that none of the above procedures bring the $\mathrm{O}_{2}$ partial pressure level up, surfacing procedures should be initiated, then one bottle should be carefully disconnected from its regulator after checking the bottle stop valve shut.

CAUTION: A SMALL AMOUNT OF HIGH PRESSURE WILL BLEED OFF AS THE REGULATOR CONNECTION IS UNSCREWED

Carefully "crack" the bottle stop valve and bleed oxygen until the $\mathrm{O}_{2}$ partial pressure reaches $170 \mathrm{~mm} \mathrm{Hg}$. Repeat this procedure each time the partial pressure is reduced to 140 
$\mathrm{mm} \mathrm{Hg}$, until the submarine is on the surface and the hatch open.

4. High $\mathrm{CO}_{2}$ Partial Pressure The normal upper limit for $\mathrm{CO}_{2}$ in the submarine atmosphere is $1.5 \%(11.4 \mathrm{~mm} \mathrm{Hg})$. Anytime that the $\mathrm{CO}_{2} \mathrm{con}-$ tent of the atmosphere approaches or reaches this level, corrective action should be taken.

The first step towards correction should normally be to take a Drager reading to check the accuracy of the $\mathrm{CO}_{2}$ Monitor. If the Monitor is defective, the dive may be continued taking Drager readings at regular intervals. If the Drager verifies the high reading, the $\mathrm{LiOH}$ canister should be replaced with a fresh canister and the blower set on HIGH until the level of $\mathrm{CO}_{2}$ is reduced below $1.0 \%(7.6 \mathrm{~mm} \mathrm{Hg})$. Inability to reduce the $\mathrm{CO}_{2}$ level and maintain it below $1.5 \%$ shall be cause for termination of the dive. If the $\mathrm{CO}_{2}$ level exceeds $2.0 \%(15.2 \mathrm{~mm} \mathrm{Hg})$ all personnel should put on emergency breathing equipment and continue to use it until the level is reduced.

\section{F. Emergency Surfacing (Jettison) Procedure}

1. General This procedure outlines the steps to be followed and the considerations to be taken into account if it becomes necessary to initiate an emergency surfacing from any depth. Such a surfacing might be necessitated due to fire, flooding or serious personnel injury. In addition, it may become necessary to jettison equipment because of entanglement or "bottomstick" in which case an essentially uncontrolled ascent is likely.

While actual jettison or release operation is simple and requires a specific action or set of actions, the decision to jettison specific equipment and the determination of the order in which to jettison require that the pilot exercise a thorough knowledge of the characteristics of the boat and the specific effects 
of each jettison action. Complete familiarization with the release and dump panel controls and the afterbody jettison mechanism is mandatory. Normally, before any equipment is jettisoned, the pilot should insure that all service weights have been dropped and the possibilities of high pressure air blow (Table IV-B) and the variable ballast system have been exhausted. A table of wet weights of jettisonable equipment is provided below:
Basket, Tool Rack, Tools, etc. - As noted on compensation sheet

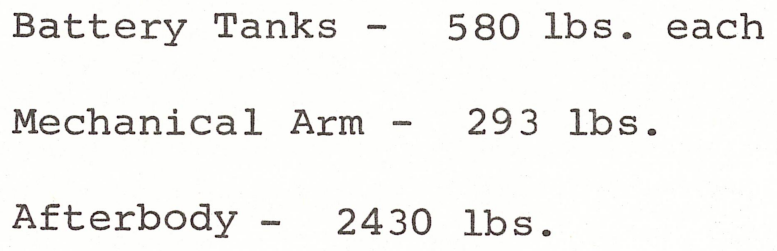

Before any jettison takes place, if time permits, the pilot should check the sphere to insure that all loose gear is secured and that the passengers are ready for the ascent. If possible the surface controller should be notified and permission to ascend obtained before any jettison action, however this will be dependent upon the nature of the problem and the urgency of the need for ascent. In any case the Surface controller should be kept advised of the status of the boat during the ascent.

2. Procedures If an emergency surfacing becomes necessary, the following precedence of actions is preferred after normal (service weights, main ballast blow and variable ballast system) procedures have been attempted. However, the Pilot in Command must use his own judgement for each specific case.
a. Release any equipment on the forward weight dropper
b. Jettison battery tank \#I
c. Jettison battery tank \#2
d. Jettison the mechanical arm
e. Jettison battery tank \#3
f. Jettison the afterbody 
Release of equipment from the forward weight dropper requires only activation of the forward weight dropper circuit. In the case of battery tank jettison however the battery hold breaker for the tank to be dropped should be opened prior to jettisoning the tank if time permits. Jettisoning of the mechanical arm requires only the activation of mechanical arm circuit, however the arm control power switch on the 30 volt bus should be opened if time permits.

During ascent, communications should be maintained with the surface controller on a fairly continuous basis if still on normal power. If on emergency power brief status reports should be made at regular intervals.

In certain instances, there could be situations where there is a need to gain buoyancy and a decision as to which equipment to jettison has no effect on safety. In this case, the pilot should weigh carefully the economic values involved, including the amount of non-operative time involved, the availability of spares, the immediate future mission requirements, the actual cost of the equipment, and procurement lead time required.

3. Special Procedures For Afterbody Jettison Due to the essentially unstable condition of the forebody during ascent, jettison of the afterbody should be preceded by careful preparation as follows:

a. Notify the surface controller of intent and if possible wait for permission to surface.

b. Secure all loose gear. Pay particular attention to heavy items such as pilots seat, emergency batteries, portable tape recorders, cameras, etc.

c. Check the emergency transponder switch activated and if time permits, that surface control is tracking it. 
d. Open master circuit breaker when ready.

e. Remove pin from afterbody release, and insert T-wrench.

f. Insure that passengers are as secure as possible and have firm handholds.

9. Rotate T-wrench through $90^{\circ}$.

During ascent it is expected that the forebody will go through a wide variety of motions and oscillations, making any action on the pilot's part impractical. If a degree of stability is attained however communication with the surface should be attempted. These communications should however be brief in order to conserve emergency battery power.

Upon arrival at the surface, the forebody may be either right side up or upside down since it is stable in either condition. This will probably depend upon its state at the moment of arrival. If the forebody is right side up, the radio should be activated and communications established. If the forebody is upside down, the underwater telephone should be used.

While on the surface, both pilot and passengers should remain as low as possible to increase the stability of the forebody. In addition it may be desirable to move high equipment to a lower position. Under no circumstances should the hatch be opened unless conditions in the sphere will not support or are hazardous to life.

4. Procedures For Egress on The Surface In the event that it is necessary to exit from the sphere, the following procedures should be used.

Sphere right side up - Move all weight to as low a position as possible, including emergency batteries. If feasible, detach science equipment and anything else that is mounted high on the science racks or stowage shelves and place 
on deck. All hands don, but do not inflate, life jackets. Wear hats if available. Brief passengers on the necessity to enter the water and stay clear of the forebody until the last person has exited and the hatch is shut and secured. The hatch should be opened slowly in case a change in position may cause the forebody to roll. While the pilot is opening the hatch the passengers should remain as low as possible. Once the hatch is open passengers should exit one at a time inflating their life jackets as soon as they clear the hatch, and proceeding immediately into the water and clear of the forebody. The pilot should distribute emergency flares, radar reflector, drinking water and space blankets among the personnel to carry topside, unless he knows that the support ship is within visual range. The pilot should carry the walkie-talkie. Upon exiting, the pilot will shut and dog the hatch. At this time, passengers may return to the forebody and use it for support, but no more than one person at a time should be completely out of the water on the forebody. If conditions warrant the pilot may consider the use of an oxygen bottle to bleed oxygen into the main ballast tank for added stability and flotation.

Sphere Upside Down - Move all possible weight to the lowest possible position, and secure it so that it cannot fall out when the hatch is opened. Don life jackets, but do not inflate. Brief passengers on the necessity for exhaling after exiting the hatch; continuing to exhale while ascending to the surface; inflating life jacket only after well clear of the forebody and remaining clear of the forebody once on the surface. Hats should be carried (stuffed inside shirt until on the surface) if available. When all preparations have been made and the surface support unit notified if possible, the emergency batteries should be turned off.

The sphere should then be pressurized to about 
three and one-half psi (apparent reading on the Altimeter will be 7700 feet). The hatch should now be undogged. The weight of hatch may jam the dogs in which case a wrench or other heavy object may be needed to drive them to the open position. The hatch will probably open forcibly. and the water level may rise into the sphere by a small amount. If so oxygen should be used to lower the water level to the outer lip of the hatch. Passengers should now exit one at a time, exhaling as they go and inflating life jackets when well clear. The pilot should increase pressure using oxygen to compensate for each passenger's displacement as he leaves. The pilot will then secure the oxygen and exit himself, taking emergency flares and drinking water with him unless he is certain of the proximity of the surface support ship. If possible the walkietalkie should be placed in a waterproof bag and taken also. Once on the surface, personnel should use the forebody to remain together but should not climb aboard as it may right itself and sink.

\section{G. Loss Of Contact}

In the event that ALVIN is on the surface and out of visual range of the support ships the following steps shall be taken.

1. Check surface identification light on

2. Check radio beacon on

3. Install radar reflector on the sail

4. During hours of darkness keep at least one underwater light on if the condition of the battery permits, otherwise use only intermittently or if aircraft or surface ships are heard or seen.

5. During hours of darkness one or two flares should be fired initially and the remainder saved for specific use such as requests on 
radio by surface ships, sighting of aircraft, etc.

6. During rough weather, one man should be stationed in the sail equipped with the spare sound powered phone, lifejacket and emergency flares, and the hatch should be kept shut. 
IV. Vehicle Performance Data

\section{A. Ascent-Descent Curves}

These curves are presented to give the pilot an estimate of vertical speed attainable for both ascent and descent utilizing various combinations of weights. The curves were derived from data taken from some 80 actual dives. Since some factors, such as actual trim at the start of the dive and temperature-density variations in the water column, are unknown there will be variations from the figures obtained from the curves; however for mission planning and general information they should be adequate. 


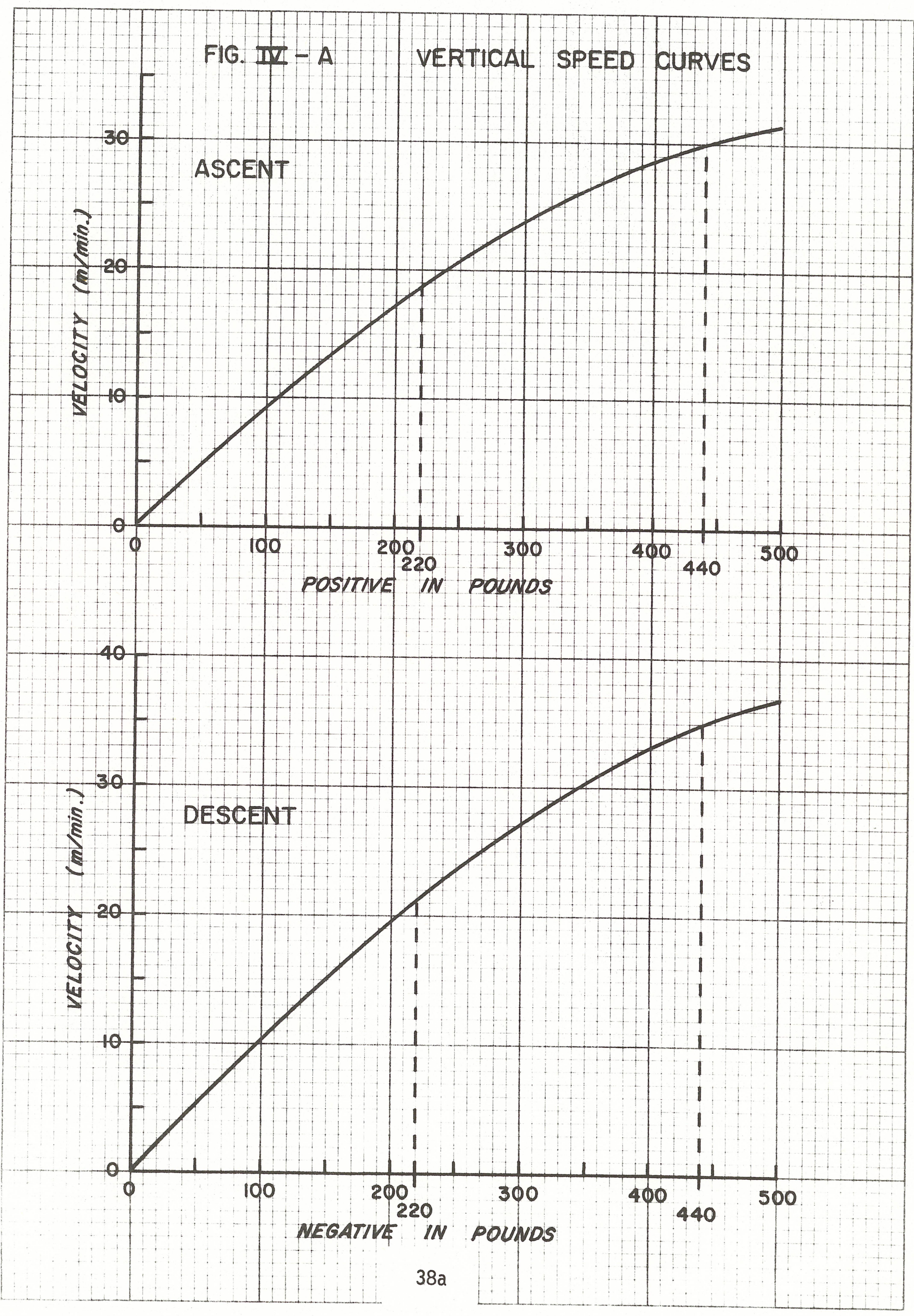




\section{B. Main Ballast Buoyancy Curves}

These curves are presented to give the pilot an indication of the amount of positive buoyancy attainable at various depths utilizing the main ballast blow system. Entering the graph with actual depth and using the curve nearest the air pressure gage reading will give the total amount of buoyancy which can be gained by blowing until tank pressure equals sea pressure. Since the entering argument is tank pressure, the curves are self-correcting for ambient temperature, however initial buoyancy may be somewhat decreased due to temperature reduction of the expanding air. This will be recovered as the air returns to ambient temperature. 


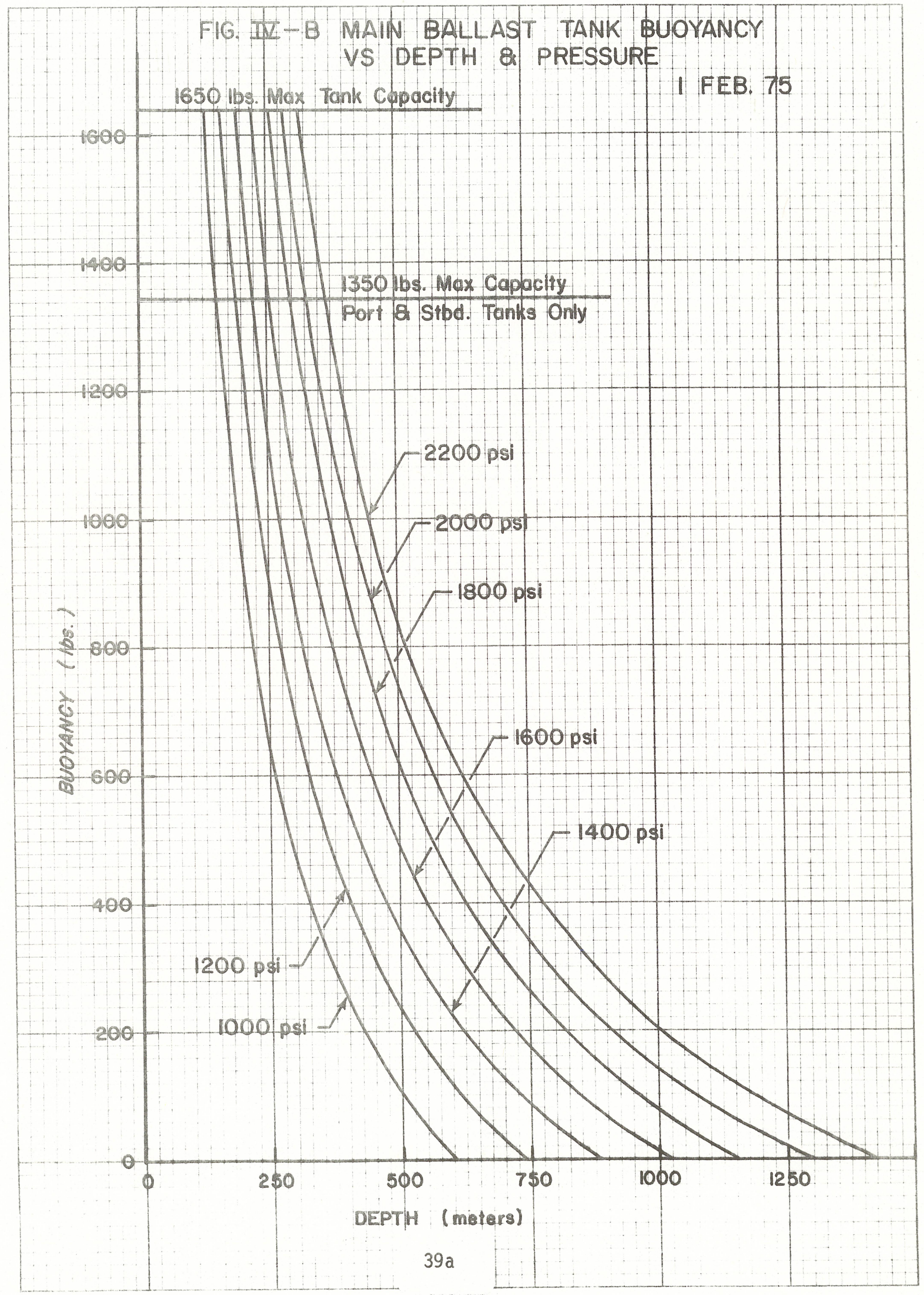




\section{Main Battery Discharge Curves}

There are two types of curves presented in this section. The first gives hours remaining until battery depletion at two specific discharge rates. Loading the battery to one of these ampere rates and comparing the voltage obtained with the appropriate curve will give the number of hours remaining at that discharge rate.

The second set of curves shows the absolute low voltage limits of the batteries and the operational low voltage limits as functions of the time since the start of the dive. The operational limit should not be exceeded except in an emergency as there is a very real possibility of cell reversal. 
FIG. IV $-6-1$

MAIN BATTERY DISCHARGE CURVES

30 VOLT BATTERY

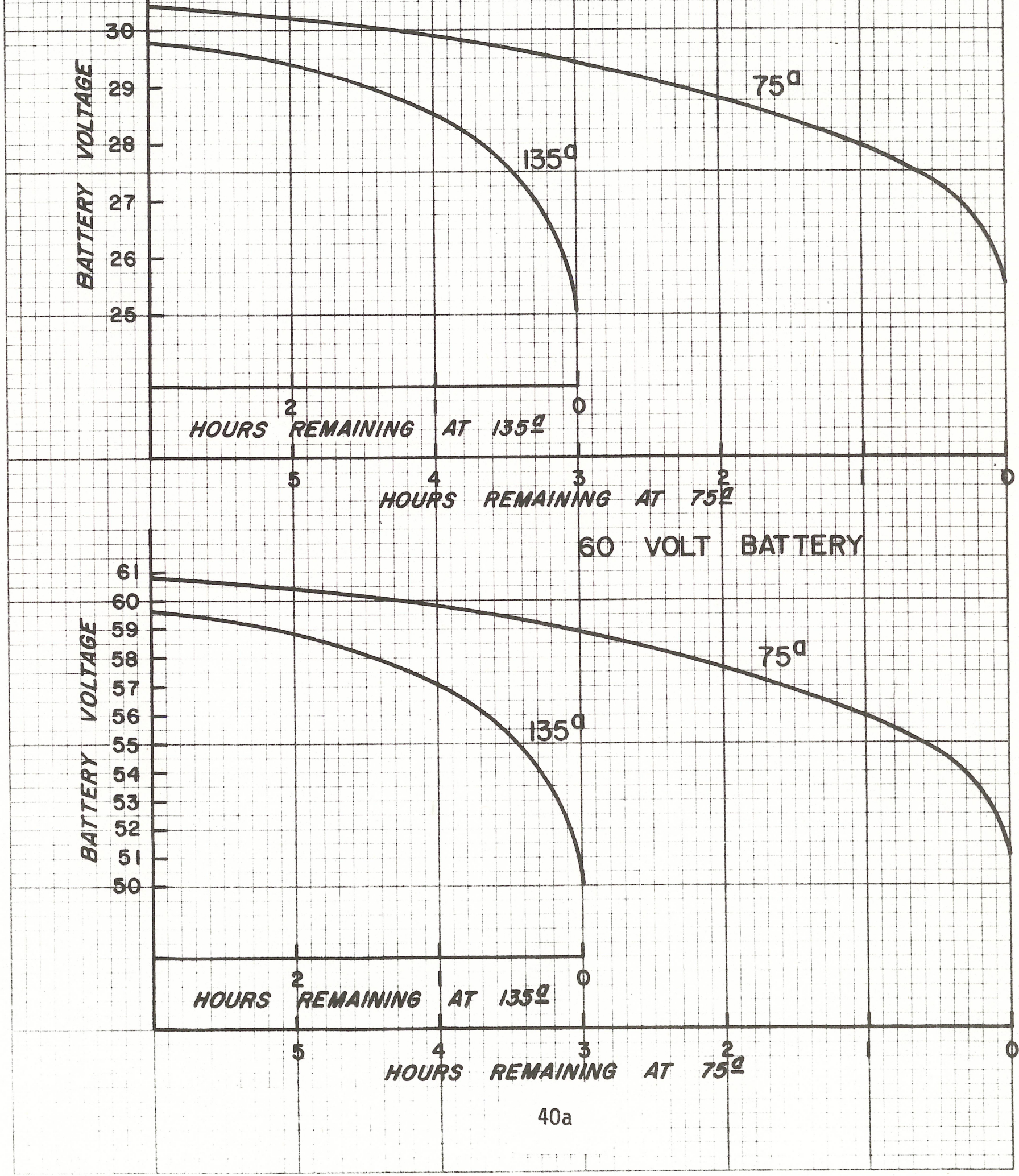




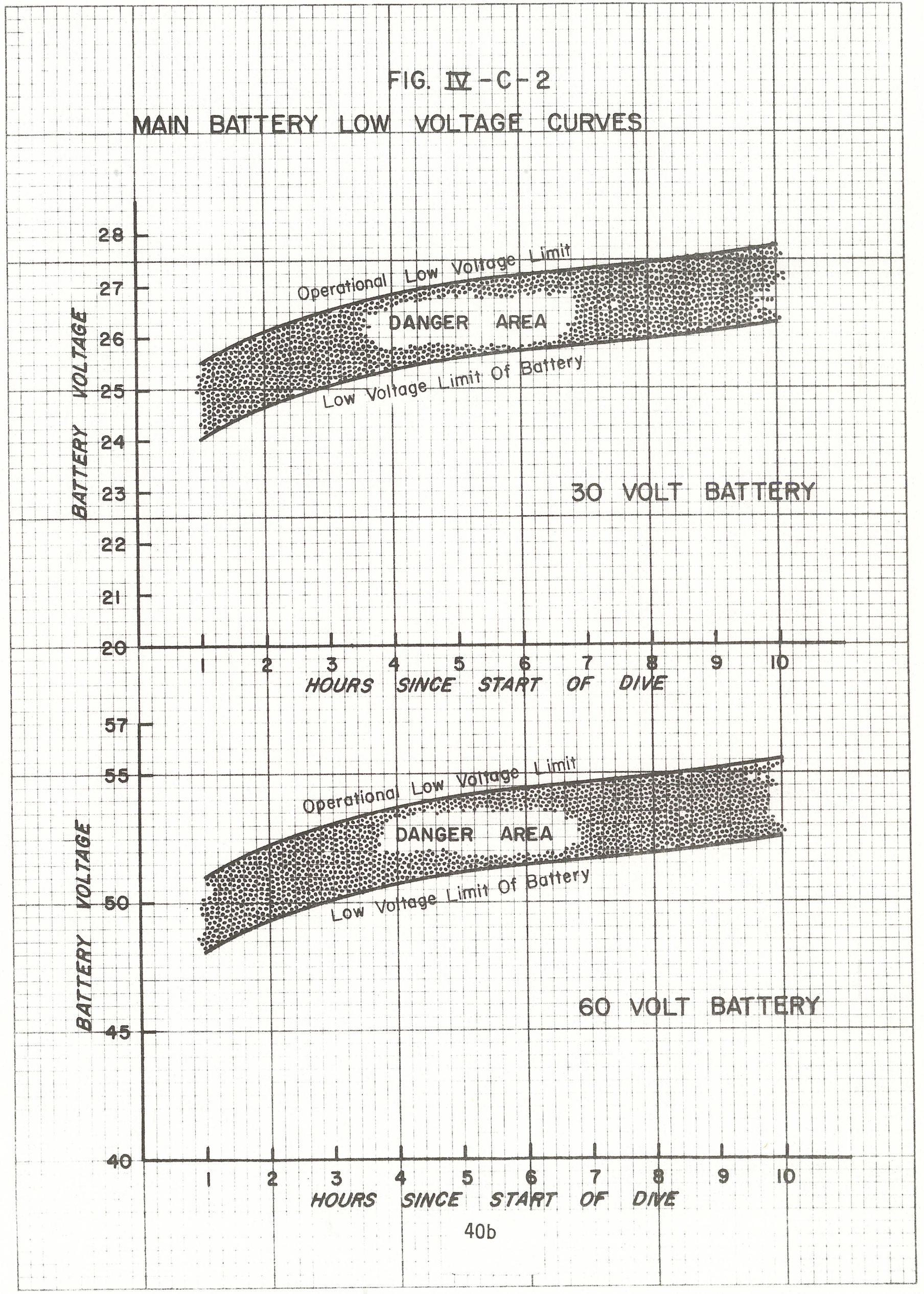




\section{Variable Ballast Curves}

There are two types of curves presented in this section. The first is for determining the actual weight of water in the variable ballast system from the variable ballast tank pressure reading and the ambient temperature. The second gives the amount current drawn by the variable ballast pump when pumping or flooding at various depths. 


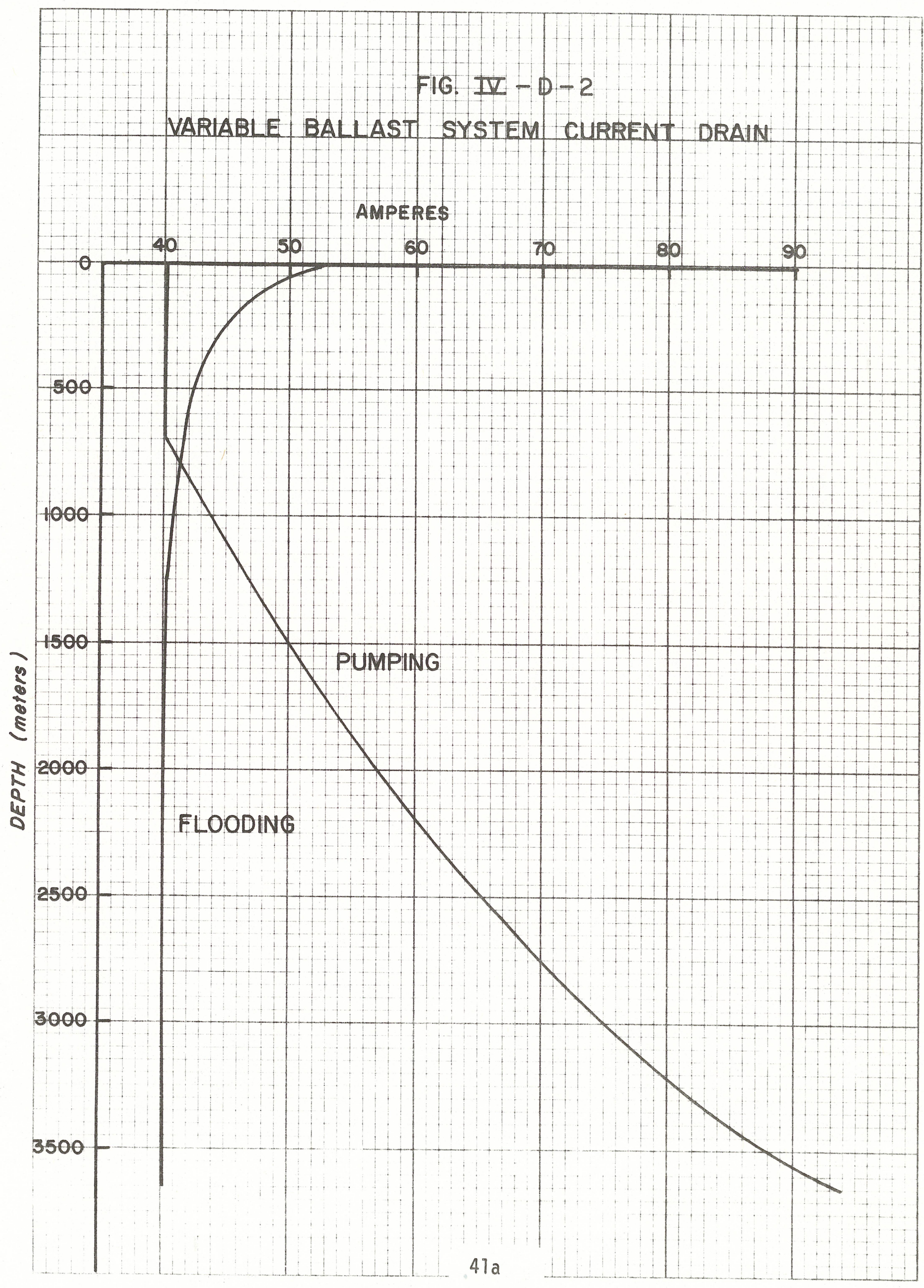




\section{Casualty Procedures and Information for Observer/ Passengers}

A. General It is conceivable that during the course of a dive, the pilot could become incapacitated due to injury or illness to such an extent that he could not operate the submarine. In such an event, the observer/passengers must have sufficient information to act on his own to surface the submarine. The purpose of this section is to provide step by step instructions for such a contingency. Before the commencement of a dive the pilot must assure himself that each of the observer/passengers understands these instructions and has adequate familiarity with the submarine controls to carry them out if necessary.

B. Power Under most circumstances the submarine can be surfaced with normal power which is already available to the service release and main ballast blow systems. If, however, normal power is lost, or if the emergency jettisons are needed, special procedures are required to provide power.

1. Emergency Power If normal power is not available, open all switches on the service bus. Locate the emergency battery with the green plug, turn on if not already on, locate the "service bus normal-emergency" switch on the forward, upper panel on the port side, lift the green cover and place the switch to "EMERG". The entire service bus is now powered by the emergency battery and individual switches may be operated in the normal manner. This includes service releases, main ballast system blow and vent, underwater telephone, pinger and emergency transponder and the carbon dioxide regenerator. Service bus voltmeter will indicate voltage available to the bus.

2. Emergency Jettison Power Red covered emergency releases, on the starboard distribution panel are powered by emergency battery only - red colored plug. These include battery tank releases, manipulator release and sample basket release. The 
only operations necessary to release one of these items is to connect the red plug to a battery pack and turn the battery pack on, lift the red cover and operate the swtich.

All three (sometimes four) emergency batteries carried are identical and interchangeable simply by moving the red and green plugs.

C. Procedures If an emergency situation develops and the pilot is unable to act, inform the Surface Controller on the underwater telephone (if normal power has been lost, shift to emergency battery as explained above). Make sure that the UP/ON switch on the underwater phone is in the UP position. You can hear the characteristic "squeek" if the phone transmitter is operable and, even though you get no reply, report everything in detail on the assumption that the surface transmitter and/or your receiver is not working. Follow the Surface Controller's instructions explicitly.

Regulations require half hourly phone checks with the surface. If communications have not been possible for a period of one hour, the surface will know something is wrong and initiate emergency procedures.

If communication with the surface is not possible, proceed as follows: (any of the following steps will surface the boat in normal trim - perform the steps in the order listed and only the minimum number of steps to get the boat moving toward the surface).

1. Operate the service release(s) (port side panel top, green covers). Lift green cover and operate momentary switch for minimum of one second. This will release remaining ascent/descent/ballast weights. These weights are normally 250 pounds each and four are carried on most dives. Service releases are on the service bus.

2. Pump variable ballast if ship's power is available (note bus voltmeters - 30 and 60 volts are both required). Switches are located below the variable ballast meter on the starboard panel. To pump, place the "hydraulic pump" switch in "AUTO" and 
when green light goes out place "ballast pump" switch to "PUMP". If water is being pumped out of the system, the VB digital and the VB panel gages will decrease. Variable ballast cannot be operated with emergency batteries. VB system is powered from the control bus.

3. Blow main ballast tanks at depths above 1000 meters ONLY. Switches are located on the forward end of the port distribution panel. Operate the "MBT blow" switch to the "BLOW" position with selector switch in "BOTH" position. Make certain vents are shut (light extinguished). Put no more than 1000 psi into the tanks. (Watch HP air pressure gage on the forward gage panel). At deep depths, little immediate effect will be noted but speed of ascent will increase with decreasing depth. Vent tanks with "vent" switch (light "on" when vents are open) for periods of from 1 to 2 seconds at about 300 meters depth and continue periodic venting until about 30 meters from the surface. This will prevent bursting tanks due to expanding air in the ballast tanks. At about 30 meters vent all air from tanks, shut vents and blow tanks completely dry (about 500 pounds of air to empty tanks of water close to the surface). You can see bubbles through the side windows when tanks are empty and air is blowing through. Boat will surface.

If submarine has not started toward the surface after execution of steps 1, 2, 3 check that red emergency battery plug is in and that battery is energized and proceed with emergency releases. Switches are red covered on upper edge of the starboard distribution panel.

4. Release sample basket. Weight will depend on loading and varies from dive to dive.

5. Drop \#l battery off the line (de-energize) by opening the \#l battery "hold" switch (lift the green cover and push the switch up to open). Hold switches are located on the upper, forward, port power panel and green covers are down when 
switch is closed. Locate red covered "emergency dump" switches, stbd. panel upper edge. Lift \#1 battery red cover and operate switch. This will drop \#l battery from the ship and lighten it by about 580 pounds.

If positive buoyancy still has not been obtained, proceed to drop \#2 battery in the same manner. Remember to de-energize batteries before dropping by opening the green-covered "hold" switches.

6. Drop manipulator by operating red covered "arm dump" switch. Manipulator weighs approximately 295 pounds in water. Drop \#3 battery.

7. As a last resort, and only if none of the above steps have succeeded in making the submarine positively buoyant, release the sphere and forebody assembly. Release mechanism is located bottom of the sphere under the small oval plate in the deck. It is necessary to remove the pin through the top of the release shaft and insert the T-handle wrench stowed at deck level, port side of science rack. Before releasing the forebody, make certain all loose gear in the sphere is secured. Read all of Section III-F-3 of this manual if time permits. Forebody is about 2400 pounds buoyant.

D. Life Support Normal life support should be adequate until you arrive back on the surface. The carbon dioxide regenerator is powered from the service bus and therefore can use either ship's power or emergency battery power. If on emergency power, the regenerator should be turned off at freguent intervals to conserve battery power. $\mathrm{CO}_{2}$ build-up can be detected immediately by monitoring with Draeger or installed monitoring device. Oxygen flow has been pre-set and should require no adjustment. Oxygen can also be constantly monitored.

In the remote event an electrical fire occurs, the atmosphere will quickly become contaminated. Immediately open the "master breaker" on the forward, upper power panel. This will secure all normal power 
to the sphere. Don the emergency breathing apparatus as instructed in your pre-dive check-out making certain the "start" lever is on. All other valves and controls are kept aligned. Use fire extinguisher if necessary. Emergency power can now be initiated on the service bus with the emergency battery. The EBA units are adequate for at least six (6) hours each.

E. On The Surface After surfacing, attempt to communicate with the Surface Controller on the support ship by radio. Turn radio switch on. Call signs are posted.

Check sound powered phones to see if swimmer is aboard. Do not open the hatch until told to do so either by swimmer on sound powered phone, or by Surface Controller by radio. If no communications due to faulty radio, and no swimmer aboard, cautiously open the hatch after determining that it is clear of the water by looking through the hatch window. Be prepared to reclose hatch at any time. The emergency $C B$ radio can now be taken topside to call the support vessel.

As noted before, a variety of surface emergency equipment is carried in the sphere including flares (day and night), radar reflector, life jackets, emergency rations, and $\mathrm{CB}$ radio. In addition, an automatic homing radio and strobe are permanently mounted on the sail and will aid the support ship in finding you without any further action. 
VI. Pilots Individual Dive Records

In order to satisfy both Navy and woods Hole Oceanographic Institution require ready reference for his fication and to pilot-in-training andion at all own records, $l o g$ in anup to date, the page should be maintain thich time a page is full DSE\&OS office for times. inclusion in the individual s pers 
- 